\title{
ARTICULANDO LETRAMENTOS SOCIAIS E ESCOLARES NO ENSINO DE INGLÊS DA EJA
}

\author{
ARTICULATING SOCIAL LITERACIES AND SCHOOL LITERACIES IN ADULT \\ EDUCATION
}

\section{Denise Silva Paes Landim ${ }^{1}$}

\begin{abstract}
Resumo: Neste artigo, relatamos os resultados de pesquisa de Mestrado (LANDIM, 2015) que investigou as relações entre letramentos sociais e escolares nas aulas de língua inglesa na modalidade Educação de Jovens e Adultos (EJA) em duas comunidades escolares localizadas na cidade de São Paulo. Os dados foram gerados por meio da observação de aulas de inglês de duas professoras, além de entrevistas formais e informais, bem como questionários. As análises se basearam nos estudos de letramentos (STREET, 2014), novos letramentos (LANKSHEAR; KNOBEL, 2011), multiletramentos (COPE; KALANTZIS, 2003 KALANTZIS; COPE, 2005, 2010, 2012a, 2012b), e letramento crítico (LUKE; FREEBODY, 1997; MONTE MÓR, 2013; MENEZES DE SOUZA, 2011) por considerarem os efeitos educacionais das mudanças sociais, culturais, econômicas e políticas advindas da globalização e das culturas midiática e digital. As análises apontaram para distanciamentos e aproximações entre ambos os tipos de letramento, evidenciando conflituosas relações entre as concepções e as práticas pedagógicas observadas.
\end{abstract}

Palavras-chave: novos letramentos; letramento crítico; Educação de Jovens e Adultos; ensino de língua estrangeira; língua inglesa.

Abstract: In this article, we report the results of Master's research (XXXXX, 2015) which investigated the relation between social literacies and school literacies in English classes of Adult Education in two communities of São Paulo city. Data was generated through observation of classes given by two teachers, as well as formal and informal interviews and questionnaires. The analysis was based on literacies studies (STREET, 2014), new literacies (LANKSHEAR; KNOBEL, 2011), multiliteracies (COPE; KALANTZIS, 2003; KALANTZIS; COPE, 2005, 2010, 2012a, 2012b), and critical literacies (LUKE; FREEBODY, 1997; MONTE MÓR, 2013; MENEZES DE SOUZA, 2011) for their consideration of the educational effects promoted by social, cultural, economical and political changes stemming from globalization and media and digital culture. The analysis pointed to distance and approximation between the two kinds of literacy, revealing conflicting relations between the observed conceptions and pedagogical practices.

\footnotetext{
${ }^{1}$ Professora Assistente do Curso de Letras Português-Inglês da Universidade Federal do Tocantins (UFTCampus Araguaína), com experiência nas disciplinas de Trabalho de Conclusão de Curso, Língua Inglesa e Estágio Supervisionado em Língua Inglesa e Literaturas. Atualmente é doutoranda do Programa de Pósgraduação em Inglês da Faculdade de Filosofia, Letras e Ciências Humanas da Universidade de São Paulo (FFLCH-USP). Atua na área de letramentos com foco na formação de professores de línguas. E-mail: denise.landim@uft.edu.br
} 
Keywords: new literacies; critical literacies; Adult Education; English as a Foreign Language; English language.

\section{Introdução}

Como efeito da globalização e da difusão das tecnologias digitais, o acesso a uma maior oferta de textos em língua inglesa ${ }^{2}$ está garantido nas práticas sociais de uma parcela cada vez significativa de pessoas. Entretanto, indagamos se o alcance dessa maior oferta de textos abrange também os alunos da Educação de Jovens e Adultos, doravante referida como EJA neste artigo, um locus marcado pela desigualdade de oportunidades de escolarização, em que permanecem as evidências de exclusão social por meio da negação aos recursos simbólicos produzidos não apenas em língua materna, mas também em língua inglesa.

Indício dessas dificuldades pode ser também verificado na quantidade pequena de pesquisas que se localizam nos anos finais da EJA, área a que a presente pesquisa se dedica, etapa em que a oferta de língua inglesa acontece. A literatura a respeito da EJA tende a debater políticas públicas e o direito à educação às populações empobrecidas, bem como as implicações da alfabetização em língua materna, sendo ainda raras as publicações acerca do ensino e aprendizagem de língua inglesa nessa modalidade. Depreende-se, a partir disso, que a aprendizagem de língua inglesa para o aluno de EJA pode não ser entendida como uma prioridade ou mesmo um direito.

Ainda assim, partindo do pressuposto de que os alunos matriculados na modalidade EJA possuem um amplo repertório de aprendizagens ocorridas fora do contexto escolar, a pesquisa teve por objetivo compreender, sob a perspectiva das teorias dos novos letramentos e multiletramentos (LANKSHEAR; KNOBEL, 2011; COPE; KALANTZIS, 2003; KALANTZIS; COPE, 2010) e letramento crítico (LUKE, FREEBODY, 1997; MONTE MÓR, 2013; MENEZES DE SOUZA, 2011), as relações entre letramento social, isto é, as práticas sociais e de aprendizagem empreendidas pelos alunos fora do contexto escolar, e suas implicações para o letramento escolar, entendido como as práticas de aprendizagem situadas no contexto escolar.

Posto que tais estudos abrangem novas concepções e práticas de linguagem, leitura, ensino, aprendizagem e práticas pedagógicas no contexto da globalização e das tecnologias

\footnotetext{
${ }^{2}$ Neste artigo, utilizaremos letras minúsculas tanto para referência à disciplina de língua inglesa quanto à língua de forma geral, uma vez que essa indistinção condiz com a premissa de que a Educação de Jovens e Adultos ultrapassa os muros da sala de aula. Tal argumento é também uma releitura de pesquisas em Linguística aplicada transgressiva ou indisciplinar, especialmente em Moita Lopes (ibid. 2006) e em Pennycook (2010), que questionam os limites das disciplinas acadêmicas.
} 
digitais, dispensamos especial atenção à existência de práticas de linguagem mediadas pelo uso de tecnologias, manifestadas em contextos que independem da escolarização, em uma relação com as práticas escolares a que os alunos estavam se habituando.

Para tanto, a investigação, de cunho etnográfico, ocorreu no contexto de duas comunidades escolares de ensino público na modalidade EJA na cidade de São Paulo, com dados gerados entre setembro e dezembro de 2012 e que resultaram na dissertação de Mestrado (LANDIM, 2015) cuja apresentação parcial de resultados se faz neste artigo.

Discutiremos neste artigo um breve histórico da EJA bem como algumas questões norteadoras acerca de seus objetivos. A seguir, teceremos algumas considerações a respeito dos estudos de letramentos. Na sequência, apresentaremos e discutiremos dois recortes dos dados da pesquisa que evidenciaram, por um lado, a aproximação entre o letramento social e o escolar e, por outro, seu distanciamento. Por fim, faremos considerações sobre as implicações da aproximação e do distanciamento, tendo em vista o construto teórico dos estudos de letramentos e as perspectivas da EJA.

\section{Contribuições dos estudos de letramentos para a EJA}

Os novos estudos de letramentos (new literacies studies) e de multiletramentos (multiliteracies) surgem no final do século $\mathrm{XX}$ como uma resposta às transformações socioculturais provocadas pelas novas tecnologias de comunicação e informação e pelos efeitos da globalização. Os estudos de letramento (literacy studies), que preconizam a aquisição e o uso da leitura de textos em contexto, são tomados como base para os novos estudos de letramento. Cervetti, Pardales e Damico (2001) ressaltam que, dentro dos estudos do letramento, apoiados no contexto social, histórico e de relações de poder, o desenvolvimento do letramento crítico se fundamenta no processo de construção do texto, atribuindo-lhe significado, em vez de extrair-lhe os sentidos. Dentro das raízes filosóficas do letramento crítico encontra-se o trabalho de Paulo Freire (1982), que, alinhado à teoria crítica social, postula a formação de um mundo mais justo subjacente à crítica aos problemas sociais e políticos, tais como a opressão e a exploração, e, como consequência, a proposição de alternativas para transformar a realidade social. Nessa perspectiva, entende-se que a linguagem é tanto o instrumento de crítica quanto o de transformação da desigualdade.

A partir da popularização das novas tecnologias digitais nos anos 1990, é premente a compreensão do fenômeno dos letramentos ocorridos sob uma perspectiva que vá além do 
suporte impresso, dando origem aos Novos Letramentos (New Literacies). A inclusão de "novos" diante do termo letramentos é esclarecida por Lankshear e Knobel (2011) como uma forma de revisitar os estudos de letramento da década de 1970, bem como um modo de ressaltar mudanças na sociedade atual. Mais recentemente, pesquisadores como Cope e Kalantzis (2003), têm adotado o termo multiliteracies, ou multiletramentos, para designar os estudos de letramentos que se expandem na negociação de múltiplos discursos, perpassados por questões de diversidade cultural e linguística em sociedades globalizadas, bem como pela multiplicidade de variedades formais de textos disponibilizadas pelas novas tecnologias de informática e comunicação. Diversidade e multimodalidade são conceitos-chave para os estudos de multiletramentos, portanto.

De acordo com Soares (2003), letramento escolar e letramento social, embora situados em diferentes espaços e em diferentes tempos, compõem os mesmos processos sociais mais amplos,

[...] o que explicaria por que experiências sociais e culturais de uso da leitura e da escrita proporcionadas pelo processo de escolarização acabam por habilitar os indivíduos à participação em experiências sociais e culturais de uso da leitura e da escrita no contexto social extra-escolar. (SOARES 2003, p. 14)

A fim de se romper com a função reprodutora da escola (BOURDIEU, 2011) e de se alcançar maiores oportunidades de transformação social, Cope e Kalantzis (2003) advogam que a pedagogia dos letramentos, preocupada com questões de diversidade, representação e multimodalidade e articulada às necessidades específicas dos estudantes, seja mais abrangente e adequada do que um estudo de língua de forma isolada, isto é, escolarizada.

Kalantzis e Cope (2005) abordam o que, em nossa leitura, seja uma intersecção entre os letramentos sociais e escolares. Em sua proposta de design de aprendizagens formais, isto é, ocorridas no contexto escolar, a partir de vivências de aprendizagens informais, localizadas no mundo extra-escolar, os autores propõem que, em vez de tratá-las como dicotomias, elas sejam abordadas como elementos que podem e devem ser sobrepostos. Desse modo, quando combinadas de forma eficiente, a aprendizagem formal e a aprendizagem informal, ou o que denominamos letramentos escolares e letramentos sociais, podem colaborar para a constituição de aprendizagens poderosas para as necessidades do mundo contemporâneo, levando-se em conta a questão das diferenças, evidenciada nos aspectos políticos, econômicos e culturais da globalização e da comunicação via tecnologias digitais. 
No intuito de alinhar letramentos de mundo e escolares para maior significado das aprendizagens escolares, os autores propõem duas condições: pertencimento e transformação. A primeira é entendida como o engajamento das identidades, dos interesses e das experiências dos aprendizes na ação educativa, na qual tem grande importância a questão da diferença, enquanto a segunda se assenta sobre o pressuposto de que trilhar sobre o desconhecido faz parte da aprendizagem efetiva. Acentua-se que, a partir dessas duas condições, a articulação entre letramentos escolares e sociais não corresponde ao silenciamento de um tipo de conhecimento para o privilégio do outro, mas a um constante e frutífero diálogo que resulta em maior significado do trabalho em sala de aula. Nesse sentido, quando a prática escolar favorece as associações entre o "mundo fora da sala de aula", a aprendizagem é não apenas significativa, mas também transformadora, além de proporcionar ao educando sair de seu lugar familiar para dialogar com outros mundos, o que se coaduna às expectativas de aprendizagem para a EJA (SÃO PAULO, 2007):

Sem desconsiderar as necessidades imediatas dos educandos - ao contrário, tomandoas como ponto de partida -, a ação educativa deve promover a superação desta situação e avançar na percepção de formas mais elaboradas do conhecimento (SÃO PAULO, 2007).

Ilustrando a relação entre o letramento social e o letramento escolar, selecionamos trecho de entrevista à professora Vívian, colaboradora da pesquisa, em que contrasta o letramento social com o letramento escolar:

\section{Trecho 1}

V: Eu amo esse trabalho [com textos]. Eu acho assim, o texto é o que está na vida. Aquele vocabulariozinho, decorar uma lista de nomes de partes do corpo, decorar uma lista de cores, uma lista, ele é necessário também? É! Só que o que que acontece? Quando o aluno recebe essa lista ele acha mais fácil. (TRECHO DE ENTREVISTA)

Ao contrastar o letramento social com o letramento escolar, a professora expõe, por um lado, o seu entendimento de que as práticas de letramento social envolvem o uso de textos, ao passo que o letramento escolar inclui práticas sistemáticas, como o estudo de listas de vocabulário. Em outras palavras, os textos são a materialidade do letramento nas atividades cotidianas (JANKS, 2014), ou, conforme a afirmação da professora, o texto é o que está na vida. Já o trabalho isolado de conteúdos, como as tradicionais listas de vocabulário, é uma parte necessária para a aprendizagem nos moldes da instituição escolar. 


\section{Breve histórico de perspectivas e expectativas na EJA}

A educação de adolescentes e adultos é iniciada já no período do Brasil Colônia, no qual a atuação dos jesuítas no campo educativo, de caráter missionário, acentua o ensino de comportamentos e conhecimentos necessários para o trabalho, sobretudo às populações indígenas e, mais tarde, aos escravos capturados na África (HADDAD; DI PIERRO, 2000). Porém, dentre variadas medidas que perpassam desde a gestão de recursos, até o pensamento desenvolvido, a educação brasileira permaneceu, por longos anos, uma atividade elitizada que não previa atingir as camadas mais fragilizadas da população.

Isso passa a ser problematizado a partir da década de 1940, apontada por Fávero (2009) e por Haddad e Di Pierro (2000) como palco de avanços para a consolidação da educação de adultos como uma modalidade com características e metas próprias no cenário educacional brasileiro. Esses autores justificam tais avanços, dentre variados elementos daquele contexto sócio-histórico: a) os altos índices de analfabetismo da população brasileira - cerca de $55 \%$ da população com idade superior a 18 anos; b) as comparações entre os índices educacionais brasileiros e os da América Latina; c) o início do processo de industrialização e da aceleração da urbanização brasileiras; d) o movimento de redemocratização do Brasil após a ditadura de 1937-1945; e) as iniciativas da recém-criada UNESCO, em 1945.

O período de 1959 a 1964 marca grandes avanços para o desenvolvimento do pensamento pedagógico da educação de adultos (HADDAD; DI PIERRO, 2000). Segundo Fávero (2009), esse período é iniciado pelos debates em que se destaca a voz de Paulo Freire, um dos relatores do estado de Pernambuco para a confecção do relatório nacional do congresso de educação de adultos de 1958, que reflete sobre a educação de adultos e as populações marginalizadas indicando o enfrentamento dos problemas sociais, tomado como ponto de partida para o processo educativo.

A partir de 1964, sob o controle do governo militar, com um "espírito modernizador" e repressor dos movimentos de contestação (SARTORI, 2011) e da educação popular (GHIRALDELLI JR, 2003), o teor político da EJA é diluído para dar lugar a um tratamento do analfabetismo como um problema atrelado aos desafios da industrialização e sua exigência de mão de obra mais qualificada, tendo no Movimento Brasileiro de Alfabetização (MOBRAL), iniciado em 1968 e extinto em 1980, seu mais evidente símbolo. 
Em meados da década de 1980, os conceitos de letramento passam a se articular à alfabetização na Educação de Adultos no Brasil, indicando os componentes ideológico, social e de poder imbricados nos atos de escrita e de fala, e que posicionam os sujeitos na dinâmica social (MOURA, 2007).

A Lei de Diretrizes e Bases da Educação Nacional (LDB), de 1996, no esteio da redemocratização pós governos militares, garante um avanço histórico para a EJA ao incorporá-la à Educação Básica, fazendo com que ela deixe de ser compreendida como educação supletiva, desconexa do ensino regular (SARTORI, 2011). Isso se ressalta com o parecer CNE/CEB 11/2000, que, partindo da concepção de educação ao longo da vida (life long learning), ressignifica a EJA atribuindo-lhe três funções (apud SARTORI, 2011, p.6976):

a) Função reparadora: visa a reparar o direito negado a tais sujeitos, reconhecendo-lhes a compensação ao conhecimento de que foram privados e cuja falta os excluiu de determinadas comunidades simbólicas.

b) Função equalizadora: objetiva dar cobertura a trabalhadores e a outros segmentos sociais desfavorecidos, cuja permanência no sistema escolar foi interrompida pela evasão ou pela repetência, de forma a assegurar uma partilha dos bens sociais que permita maior igualdade na sociedade.

c) Função qualificadora: identificada como a função efetiva da EJA, respalda-se no traço de incompletude humana, que se renova, amplamente, dentro e fora da escola. Indica que em todas as idades e em todas as épocas da vida, é possível se formar, desenvolver e construir conhecimentos, habilidades, competências e valores que conduzam à realização de si e ao reconhecimento do outro como sujeito.

Cumpre realçar, entretanto, os perigos da adesão acrítica à educação ao longo da vida como premissa básica da educação de jovens e adultos. Se, por um lado, os preceitos da educação ao longo da vida permitem liberdade para o trabalho com princípios de autonomia e agência aos educandos de EJA, por outro, eles podem mascarar a situação de exclusão vivida pelo aluno de EJA. Além disso, os princípios da educação ao longo da vida nos parecem articulados aos do capitalismo veloz e global, exigente não apenas de mão de obra, mas de consumidores qualificados, isto é, sujeitos flexíveis em prontidão para o consumo rápido de novos produtos, estilos e modos de ser no mundo. Em razão disso, reiteramos a necessidade 
de prática de letramento crítico, originada, dentre outros, na proposta de Freire (1982), conforme discutido acima.

As atuais diretrizes para o ensino de língua estrangeira na EJA nas escolas municipais de São Paulo (SÃO PAULO, 2010) também se preocupam em articular as aprendizagens escolares a um conhecimento informal situado na experiência de mundo dos alunos, entendoas como parte de um projeto que prepara o aluno para a vida em uma determinada sociedade. Evocando princípios filosóficos acerca da língua, sobretudo seu aspecto situacional e contextualizado, cujos significados implicam relações sociais, históricas, culturais e de poder, as diretrizes preconizam a relação de alteridade e identidade proporcionada pela língua estrangeira e a busca por notar as posições sociais nas quais os aprendizes estão. Postula-se também a compreensão de língua como um fenômeno de múltiplas faces em operação, como as funções comunicativas, as estruturas gramaticais, a adequação a um contexto, o léxico, a construção de sentidos em um texto articulada ao contexto, dentre outros.

Diante disso, entende-se, na leitura dessas diretrizes, que aprender uma língua é aprender a usá-la nesses múltiplos aspectos, o que sugere que as atividades pedagógicas, as técnicas e as abordagens devam contemplar a variedade de aspectos que compõem a língua. Indica-se, portanto, uma prática pedagógica que concilie a educação e a formação dos alunos por meio da aprendizagem crítica e relevante da língua estrangeira, situando-a em um contexto, conforme os pressupostos dos estudos dos novos letramentos (COPE; KALANTZIS, 2003; GEE, 2004; MENEZES DE SOUZA, 2011; LANKSHEAR; KNOBEL, 2011; JORDÃO, 2012, 2013; MONTE MÓR, 2013, entre outros).

\section{Apresentação da comunidade investigada e da metodologia de pesquisa}

Os dados foram gerados em duas comunidades escolares, compostas por duas professoras e suas turmas de inglês na EJA, entre setembro e dezembro de 2012.

O Centro Educacional Transdisciplinar ${ }^{3}$ é uma escola que oferta exclusivamente a modalidade $\mathrm{EJA}^{4}$ em seis turnos diários, com uma organização curricular diferenciada, centrada em áreas de estudo integrado, em vez das tradicionais disciplinas. Por isso, observamos, nesta comunidade escolar, as aulas de Linguagens e Códigos da professora

\footnotetext{
${ }^{3}$ A fim de preservar-lhes a identidade, os nomes das escolas foram substituídos por pseudônimos.

${ }^{4}$ Além dela, existem outras 15 escolas desse tipo na cidade de São Paulo, de acordo com informações disponibilizadas em http://portal.sme.prefeitura.sp.gov.br/Main/Page/PortalSMESP/Educacao-de-Jovens-eAdultos Acesso em: 13 dez. 2017.
} 
Vívian ${ }^{5}$ Essas aulas apresentavam conteúdos equivalentes aos de língua portuguesa, língua inglesa e artes. Já a Escola Municipal Paulo Freire é uma escola regular que oferece os cursos do currículo disciplinar tradicional, ofertando as aulas de EJA no período noturno. Observamos, nesta escola, as aulas da professora Milena.

O trabalho consistiu em pesquisa qualitativo-interpretativa, recorrendo-se a procedimentos associados à etnografia, escolha metodológica que se justifica por promover a busca de significados de ações ocorridas em uma comunidade escolar específica. Foram utilizados os seguintes instrumentos de geração e registro de dados: observação participativa de aulas e do ambiente escolar, diário de campo, questionários escritos e entrevistas semiestruturadas com professores e alunos colaboradores. A interpretação dos dados foi norteada pela tentativa de capturar a lógica que rege as práticas pedagógicas de determinada comunidade escolar, observando-lhe os valores, os hábitos, os comportamentos e as ações dos sujeitos nela envolvidos (DUBOC, 2007).

\section{Distanciamentos: dos eixos temáticos à restrição do uso do inglês ao léxico}

De acordo com os pressupostos da educação básica em Brasil (2013), a organização curricular em disciplinas pode sofrer intervenções epistemológicas, pedagógicas e didáticometodológicas, como a pluridisciplinaridade, a interdisciplinaridade, a multidisciplinaridade e a transdisciplinaridade. $\mathrm{O}$ referido documento conceitua a interdisciplinaridade como uma abordagem epistemológica que integra diferentes disciplinas em um trabalho cooperativo, de abertura para o diálogo entre diferentes sujeitos, saberes, ciências e temas. Tal diálogo integrador é operado pela organização didático-pedagógica em torno de eixos e projetos temáticos, também entendida como transversalidade.

Tais pressupostos vão ao encontro das epistemologias da pós-modernidade por diluírem fronteiras de categorias do saber, tornando-as flexíveis, situadas e realizadas na própria ação educativa, o que também permite a seus praticantes que lidem com seus inerentes conflitos (KALANTZIS; COPE, 2012b).

Sendo a EJA uma modalidade de educação dedicada ao bem público, os objetivos de sua ação pedagógica subjazem a ação política para que educandos construam conhecimentos úteis à compreensão do processo produtivo, permitindo-lhes a participação e a intervenção na

\footnotetext{
5 Adotamos pseudônimos para nos referirmos às professoras, a fim de preservar suas identidades. Nas transcrições de falas das professoras, utilizamos a letra inicial desses pseudônimos. Letras seguidas de números representam os alunos em substituição a seus nomes.
} 
vida social (SÃO PAULO, 2010). Dito de outro modo, a proposta de ensino integrado entre as disciplinas é condizente com propostas educacionais preocupadas com o papel formador da instituição escolar ante as mudanças na organização da sociedade contemporânea, conforme os pressupostos dos estudos de novos letramentos (KALANTZIS; COPE. 2005). A proposta de integração de conhecimentos e métodos é considerada um facilitador para os estudantes e pode beneficiar o público da EJA, por levar em conta seus saberes desenvolvidos ao longo de suas experiências de vida. Em consonância com as expectativas de aprendizagem na modalidade EJA no Brasil (BRASIL, 2013) e em São Paulo (SÃO PAULO, 2010), em ambas as comunidades investigadas, notamos ações educativas norteadas por eixos temáticos.

Entretanto, a organização das práticas escolares sob eixos temáticos não ocorreu de forma regularizada aproblemática. Portanto, discutiremos nessa seção duas ocorrências dessa organização que entendemos como provocadoras de distanciamento entre os letramentos sociais e escolares dos estudantes.

O primeiro excerto discutido foi extraído de uma sequência de aulas da professora Milena na Escola Municipal Paulo Freire e está inserido em um projeto desenvolvido por toda a escola. O projeto contou com a parceria de uma companhia de energia elétrica, cujo objetivo foi o de conscientizar a comunidade escolar para a necessidade de desenvolvimento de ações de sustentabilidade acerca do consumo de energia elétrica. O escopo de atividades selecionadas para o trabalho de língua inglesa foi composto por dois momentos: 1) discussão de expressões e vocábulos em torno de fontes de formas de energia; 2) seleção de imagens no mecanismo de buscas online Google, para a produção de um portfólio de fontes de energia, articulado à disciplina de Geografia. Embora diferentes entre si, ambas as atividades enfocam o sistema lexical da língua. Reproduzo abaixo as anotações de diário de campo referentes à primeira aula da sequência de atividades.

Trecho 2

Milena introduz o assunto de energia perguntando o que os estudantes estão estudando em ciências. Os alunos respondem que estão estudando sobre energia. A professora então escreve na lousa: "Where can we find energy?", com a tradução em português.

A partir disso, os alunos fazem colaborações em português, que são reformuladas pela professora em inglês. Ela anota os exemplos dos alunos na lousa, com a tradução. Além disso, $\mathrm{M}$ mescla português com inglês em sua fala, com produções como: nosso body; a light que está funcionando, o fan que está desligado. Outros exemplos de expressões que a professora utiliza em inglês: At home, DVD, microwave, computer, radio...

C1: E o ferro de passar roupa? [E fala para a colega] Hoje passei muita roupa.

$M$ escreve na lousa iron. Pergunta: "E onde vocês trabalham, tem energia? Quem trabalha em indústria?"

C2 fala que em seu trabalho tem um gerador, usado quando a energia acaba. 
M então, pede que os alunos não copiem as perguntas e respostas da lousa, apenas prestem atenção. Diz que depois terão tempo. Escreve na lousa: "What do we do without evergy?"

M: "Dá pra watch TV, ouvir o radio? E à noite? O que fazer? Sleep? Não tem a soap opera."

C3: "É que estamos muito acostumados."

M escreve mais uma pergunta na lousa: "What do we use it for?", com a tradução em português. Conforme alunos respondem em português, $\mathrm{M}$ anota em inglês na lousa: To light our houses, To cook and heat food. To iron clothes.

M enfatiza a pronúncia de "iron". Explica que iron pode ser tanto o "ferro" quanto "passar roupas". Um aluno pergunta pela palavra "grill” e M. explica que grill é grelhar.

Alunos pedem para copiar. M. autoriza a cópia e mostra na lousa que onde ela marcar $\mathrm{X}$, os alunos devem pular uma linha no caderno.

M explica que na próxima aula a turma irá ao laboratório de informática fazer pesquisa de vocabulário em conjunto com as aulas de geografia. Um aluno diz "Aí, sim!"

M sugere escrever no caderno como se falam/se pronunciam as palavras entre barras, para não confundir com a grafia correta.

(DIÁRIO DE CAMPO) - aula na $3^{\text {a }}$ Etapa A (tipos de energia)

Após o registro das questões, Milena explicava ou traduzia seu significado e, em seguida, pedia para que os alunos respondessem o que acontecia em português. Além das perguntas norteadoras em inglês, os estudantes foram solicitados a registrar, em seus cadernos, vocábulos relacionados às formas de obtenção de energia disponíveis no Brasil. As perguntas norteadoras, embora apresentadas em inglês, não foram objeto de estudos ou sistematizações, apenas disparavam as indagações sobre as quais os alunos se engajaram a debater. Dessa maneira, a intersecção entre o projeto da escola, ou seja, o tema macro em desenvolvimento em todas as disciplinas, e as competências micro, específicas à aula de inglês, foi realizada no enfoque dado ao vocabulário, embora cada parte da atividade tenha nuanças refletoras de concepções de língua e de articulação entre o letramento social e o escolar.

Por um lado, a primeira atividade, destinada a discutir formas de obtenção de energia e de seu uso na rotina, proporcionou alto envolvimento por parte dos estudantes, mobilizando, em um diálogo coletivo e bilateral, conhecimentos advindos de letramentos sociais para o desenvolvimento de posturas e decisões ante os problemas do cotidiano. Estimulados a buscar vocábulos para nomear elementos de seu dia a dia no novo idioma, os estudantes diziam palavras e expressões em português, reformuladas pela professora para o inglês, o que os colocou em situação análoga a um jogo entre eles e a professora. Por outro lado, a ênfase da ação educativa, assumida como um recorte derivado de escolhas, volta-se para o léxico no estudo da língua estrangeira, com a tradução de vocábulos por parte da professora na primeira 
parte da sequência didática e na seleção de imagens, orientada pelas palavras, para o portfólio de geografia.

Notamos, porém, uma diferença relevante entre as atividades desse projeto. A proposta de buscar imagens para compor o portfólio de geografia compõe uma prática de letramento escolar que, além de ter caráter interdisciplinar, se apoia no letramento social dos alunos, uma vez que a construção de sentidos proporcionada pela leitura de imagens implica a apreensão conforme a experiência e o saber de quem as vê. Aliando-se tal perspectiva às dos estudos de letramento, a compreensão e a interpretação de imagens, da mesma forma como ocorre com o sistema simbólico verbal, implicam-se em um determinado contexto histórico, social e cultural, conforme o apontamento de Ferraz (2012). Para a pedagogia de multiletramentos, como em Kalantzis e Cope (2005), esse é um trabalho a ser realizado na escola, visto que o emprego e a leitura de recursos semióticos de variados meios refletem a complexidade e a riqueza das novas mídias presentes na sociedade contemporânea.

Conforme apontado acima, Milena, ao propor que os alunos recorressem às imagens a fim de compreender os itens que compororiam o portfólio, ativou conhecimentos inseridos nos letramentos sociais dos alunos, dada a contextualidade da compreensão de imagens. Ultrapassou-se, dessa maneira, o evento de sala de aula. Entretanto, alertamos para o perigo da focalização no léxico como o único articulador entre a disciplina de língua inglesa e o projeto escolar, uma vez que ela pode comprometer a reflexão quanto a aspectos importantes do contexto e da noção de texto dos quais os elementos lexicais são elementos constitutivos.

Gee (2004) e Reagan (2009) acentuam, a esse respeito, que palavras isoladas não possuem definições generalizáveis, tais quais as apresentadas em dicionários, aceitáveis em qualquer contexto, mas operam e se modificam em função deles. Para Gee (2004), o conhecimento do significado geral de palavras é praticamente infrutífero sem a apreensão do emprego delas em contextos. Ante o desconhecimento ou a desconsideração das diferenças entre usos e traduções de palavras em contextos variados, é previsto que se resulte na compreensão equivocada de que existem equivalências exatas entre os vocábulos, o que pode levar à noção de que os vocábulos e as expressões existem por si só, precedendo seu uso por parte de usuários diferentes em contextos, textos e modalidades distintos.

$\mathrm{Na}$ ausência do tratamento sobre os contextos de uso dos vocábulos nas diferentes línguas, ainda que isso aconteça por meio de breves discussões, ou mesmo sem outras atividades em que tais diferenciações pudessem ser evidenciadas, preserva-se uma concepção 
de linguagem como sistema abstrato, antecedendo os usuários. Além disso, recai-se no modelo autônomo de letramento, isto é, distanciado de implicações sociais e ideológicas existentes nos textos e nas práticas e eventos de letramento, segundo Street (1983 apud BARTON, 1994).

A seguir, trataremos de um excerto pertencente à comunidade escolar Centro Educacional Transdisciplinar, na aula da professora Vívian. Semelhantemente à atividade analisada acima, a atividade em questão refere-se a um projeto escolar trabalhado nas demais disciplinas - ou áreas, de acordo com o que esta escola específica estabeleceu como organização curricular, a qual se coaduna aos estudos de inglês via sistema lexical.

Segue abaixo o trecho a ser discutido:

Trecho 3

Aula dedicada à comemoração do Dia das Crianças na escola toda, com uma exposição de brinquedos e brincadeiras de crianças no salão principal.

Nas aulas anteriores, Vívian já havia solicitado que os estudantes trouxessem um brinquedo para participar da exposição do Dia das Crianças. A maioria dos alunos já havia trazido suas colaborações ao longo da semana, mas alguns trouxeram no dia da exposição.

$\mathrm{Na}$ aula desse dia, a professora recolhe e elogia os trabalhos.

Em seguida, escreve na lousa: CHILDHOOD, CAR, KIDS, KITE, DOLL, BALL, TOYS, DOLL'S HOUSE. (às 7:34)

V: "Pessoal, deem uma olhada nessas palavras em inglês. O que é KIDS?"

A1: KIDS é criança.

A2: TOY é brinquedo, referente ao filme.

A3: By CAR.

V: Até já estudamos essa palavrinha. Como é que você vai para a escola?

A3: By CAR.

A1: Já vi essa palavra em brinquedo de criança. [Sobre a palavra CHILDHOOD]

$\mathrm{V}$ desenha KITE, DOLL, KIDS, BALL, TOP na lousa.

A4: Pode copiar? (às 7:41)

$\mathrm{V}$ diz que alunos podem copiar.

Às 7:47 subimos para o $3^{\circ}$ andar da escola, para participar da exposição de brinquedos. Lá, há alunos de todas as turmas participando e interagindo com os trabalhos, como os vai-e-vem, bambolês, dominós, feitos pelos próprios alunos, com materiais reciclados.

ANOTAÇÕES DO DIÁRIO DE CAMPO - Aula na $3^{\text {a }}$ Etapa A (Dia das crianças) em 10/10/12

O projeto, comemorativo do dia da criança, teve por finalidade valorizar as identidades dos alunos por meio de leituras e narrativas sobre suas memórias de infância. Além disso, objetivou a conscientização sobre a sustentabilidade por meio da reciclagem de materiais descartados. Em Linguagens e Códigos, sob a condução da professora Vívian, a sequência de atividades envolveu os seguintes aspectos: discussão sobre sustentabilidade; seleção de materiais reciclados; planejamento e confecção de um brinquedo, exposto no evento citado; a 
apreciação de trabalhos dos colegas; participação em brincadeiras coletivas, ciranda e cantigas de roda; narrativas de memórias de infância; leitura de texto sobre a infância; em específico na área de inglês, elaboração de lista de brinquedos nesse idioma. Como recurso para ensinar alguns desses vocábulos, Vívian fez desenhos na lousa.

Como se evidencia na descrição acima, subjacente às aulas de Linguagens e Códigos, a multiplicidade de linguagens e de letramentos, tanto sociais quanto escolares, caracterizou as atividades e garantiu, segundo minhas observações, alto engajamento por parte dos alunos. Porém, no estudo de inglês, a multiplicidade dá lugar à já conhecida lista de vocabulário pertencente às práticas de letramento escolar. A estratégia de associar palavras em inglês aos desenhos, provavelmente como forma de facilitar a associação entre o significante e o significado, revela um traço de multimodalidade - e que se constitui como elemento adicional à lista de palavras -, presente nas práticas de letramento social, sob os moldes do letramento escolar, conforme já discutido acima.

Diferentemente da aula de Milena, sobre as fontes e usos de energia, Vívian protagoniza a escolha sobre quais as palavras serão estudadas e associadas a um significado, ou tradução. O que chamamos de situação análoga a um jogo entre a professora e os alunos ocorre, aqui, de forma inversa ao que vimos na aula da professora Milena. Na aula da professora Vívian, os alunos devem empregar estratégias, conhecimentos de mundo e do idioma estrangeiro para atender às expectativas da escolarização e para engajarem-se à prática de letramento escolar.

Chama a atenção, entretanto, a explicitação de estratégias dos alunos A2 e A3, recorrendo ao letramento social de que dispõem, nos trechos: “A2: TOY é brinquedo, referente ao filme. A3: By CAR."

A2 demonstra que seu conhecimento da palavra toy vem de um contexto, provavelmente o filme Toy Story - Um mundo de aventuras (1995), conhecido no Brasil pelo título em inglês. Semelhantemente, a aluna A3 utiliza a palavra car antecedida pela preposição by, empregando a locução adverbial de modo e evidenciando sua construção de sentidos quando se fala sobre meios de transporte. Manifesta-se, deste uso, uma situação de letramento escolar à qual a aluna pode ter se engajado anteriormente. Reforçando essa hipótese, Vívian, responde que o tema dos meios de transporte já havia sido estudado: "V: Até já estudamos essa palavrinha. Como é que você vai para a escola? A3: By CAR.” 
Enquanto a professora acentua a palavra, ao invés da locução adverbial completa, a compreensão da aluna caracteriza um contexto, isto é, uma prática de letramento escolar em que se estudou o tema meios de transporte. A evocação de letramento social também é evidenciada quando A1 diz já ter visto a palavra childhood em um brinquedo para crianças.

Do trecho acima, verifica-se que o letramento escolar, caracterizado pela linearidade, em que cabe a insistência no ensino de palavras descontextualizadas, confronta-se com o letramento social do aluno, cujo cotidiano tem recebido cada vez mais incorporações de usos de língua inglesa, como é o caso em que se retoma o título de uma produção cinematográfica estrangeira nesse idioma.

Avaliar as inserções da língua inglesa no cotidiano dos brasileiros e outros povos não falantes de inglês como primeira língua e suas implicações corresponde a uma das expectativas de aprendizagem de língua estrangeira na modalidade EJA (SÃO PAULO, 2010), o que se articula aos estudos dos novos letramentos, conforme defende Menezes de Souza (2011), como parte do exercício crítico de "ouvir-se ouvindo", ou seja, de ter em conta as relações entre as interpretações do aprendiz e o contexto social de que esse faz parte. Porém, as inserções parecem apenas constar como uma forma de entender as palavras que a professora selecionou, sem reflexão sobre a razão de a aluna já conhecer algumas palavras, o que se configura como um exercício de letramento crítico. Compreendemos que o conhecimento e o letramento social do aluno, neste processo, não são acionados de forma a se articularem ao letramento escolar, mas servem como referência para atender ao propósito de responder às expectativas da escola, representada pela prática da professora, testando os conhecimentos dos alunos (BARTON, 1994).

Embora se ressalve que o ambiente de aprendizagem em ambas as atividades tenha sido propício ao diálogo bilateral, e que houve pequenas inserções de letramento social para promover o letramento escolar, as atividades focalizadas no léxico implicam, sobretudo na modalidade da EJA, uma diminuição das oportunidades de aprofundamento e reconhecimento do uso social da língua inglesa, em especial a sua variedade de modalidades, usos e contextos, o que proporciona maior ciência sobre aspectos sociais, políticos e culturais inerentes à língua, em consonância com as expectativas de aprendizagem da EJA e aos pressupostos da pedagogia de letramentos, isto é, o exercício da cidadania em uma sociedade complexa, bem como a perspectiva de mobilidade social. 


\section{Aproximações: abordagem da cultura midiática e de canções}

A partir de meados do século XX, o cotidiano de uma parcela significativa da população se modifica em razão de demandas socioeconômicas advindas do declínio da indústria no século XX, conforme Hall (1997). Segundo o autor, práticas e cotidianidades locais sofrem mudanças ao entrar em contato com o sistema midiático que se quer global, trazendo para a rotina das pessoas mensagens e discursos capazes de provocar alterações na compreensão de mundo e na construção de significados, inscritos na cultura. Com a mundialização do sistema midiático, o caráter híbrido da cultura é evidenciado, articulando localidades e as supostas globalidades ${ }^{6}$.

Inscrita e operando no interior do jogo de poder, a educação é também uma instância da cultura, uma vez que se refere aos processos pelos quais a sociedade incute normas, padrões e valores, de modo que as gerações futuras ajam de acordo com os valores e normas compartilhadas pela geração de seus pais e pelo sistema de valores predominante (HALL, 1997).

Considerando o que foi exposto acima, a questão das aprendizagens mediadas por artefatos midiáticos contribui para a discussão da relação entre as práticas de letramento social e os saberes valorizados e legitimados pela instituição escolar. Segundo Rocha e Maciel (2013), tal relação passa a ser questionada no âmbito educacional, centralizada na discussão a respeito de que tipo de conhecimento deve ser valorizado nas práticas de escolarização. Entretanto, a partir dos anos 1960, o questionamento assume o foco de "o conhecimento de quem vale mais".

Considerando que as mídias digitais e analógicas cumprem importante papel para a formação e a informação de uma rede cultural de disputas pelo poder, questões de representação e identificação, subjetividades e uma certa sociedade que se deseja construir (GIROUX; SIMON, 1989), o trabalho com mídias contribui para a elaboração de ação pedagógica e crítica, significativa às necessidades dos estudantes. $\mathrm{O}$ acesso a informações, dispostas nos meios não escolares, como a mídia e a internet, ocorre de uma forma nunca antes percebida.

A discussão de Fernandes (2008) se aproxima das preocupações dos estudos de letramentos, a respeito do uso de canções no ensino de línguas, maternas ou estrangeiras, por acentuar a oportunidade de aprendizagem acerca da cultura e do contexto sócio-histórico que

\footnotetext{
${ }^{6}$ As ditas globalidades são localidades, porém ganham tal status em função de relações de poder que, inclusive, se atualizam por meio de sua difusão midiática.
} 
subjazem a produção musical estudada, bem como o uso de temas transversais. Além de garantir elementos linguísticos articulados em textos completos, como a oralidade, as rimas, o léxico, os tempos verbais, dentre outros, é possível discutir o contexto que envolve a produção e a recepção da canção.

Nesse escopo, selecionamos e discutimos duas atividades didáticas que se articulam à questão da difusão midiática e do uso de canções. A primeira delas, um trabalho realizado pela professora Milena com a canção "Strange Fruit", interpretada por Billie Holiday, mobiliza o letramento de mundo dos alunos por explorar o tema do racismo, por ocasião da comemoração do Dia da Consciência Negra, feriado municipal ocorrido dois dias antes da aula em questão.

Detentora de forte teor de protesto, a canção descreve o linchamento de um negro pendurado a uma árvore, o "fruto estranho" que intitula a canção. A canção se baseia em um poema de Meeropol, escrito em 1937 e inspirado na fotografia de Lawrence Beitler, de 1930, em que se veem os corpos de dois jovens negros linchados e pendurados a uma árvore, acusados de terem matado um homem branco e estuprado sua companheira ${ }^{7}$. A história subjacente à canção é contada aos alunos durante a aula, depois de realizada a atividade. Um aluno, inclusive, diz querer conhecer outras canções de Billie Holiday e que o faria utilizando a internet.

A aula é iniciada com a justificativa da professora, conforme se compreende do trecho abaixo:

\section{Trecho 4}

M: O que é importante a gente pensar nesse dia?

C1: É o aniversário de...

M: Happy Birtyhday. Parabéns [...]. Pergunto para vocês pra gente pensar no dia da Consciência Negra e por que ele existe. E a gente pensar aqui no nosso Brasil. No Brasil, existe preconceito, existe preconceito, existe racismo?

(Alunos falam ao mesmo tempo): Existe. Sim.

M: Muito, pouco ou mais ou menos?

Alunos: Muito.

M: Tá. E nos Estados Unidos? Vocês acham que tem racismo ou não?

Alunos: Tem.

M: Muito, pouco ou mais ou menos?

Alunos: Muito.

M: Muito? Se bobear, mais do que o Brasil até. Mas uma coisa que é complicado aqui, que é diferente de lá é que as pessoas, não só em relação ao racismo, ao preconceito de cor, mas as pessoas, em geral, no Brasil são mais discretas em relação aos preconceitos. Elas abafam, elas escondem os preconceitos. De repente, estou conversando com um amigo meu e "Ah, não, eu não tenho preconceito, mas...” Aí, a pessoa começa a falar e eu percebo quais são os mas. [...]

\footnotetext{
${ }^{7}$ Fonte: http://www.theguardian.com/music/2011/feb/16/protest-songs-billie-holiday-strange-fruit. Acesso em: 19 out. 2014.
} 
Brasileiro é assim. Não estou falando que vocês são assim, estou falando mais em geral. Nos Estados Unidos, eles escancaram muito mais o que eles são, em relação a preconceito racial. Se acha que determinada etnia é inferior, eles deixam isso claro. Não sei o que é pior, uma pessoa que é preconceituosa e esconde, você não sabe quem é essa pessoa de verdade, ou uma pessoa que fala "porque eu acho que negro é isso mesmo". Os dois são terríveis, na minha opinião.

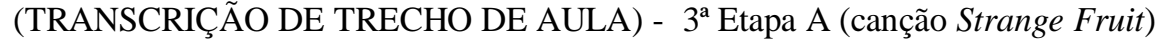

A seguir, a canção é tocada pela primeira vez com o objetivo, conforme instruções de Milena, de apenas ouvir para perceber a melodia e seu possível significado. Na sequência, Milena pergunta quais palavras vieram à mente ao ouvir aquela canção. Os alunos respondem com palavras como: sentimentos, tristeza, emoção e velório.

Após o compartilhamento dessas palavras compartilhadas entre os alunos, a professora passa a uma etapa de trabalho com a linguagem verbal da canção, explicando que a melodia possui uma estreita relação com a letra da música, que é também triste e fúnebre. Dando sequência, Milena apresenta, na lousa, a seguinte lista de palavras, instruindo os estudantes a tentar identificar quando ouvissem a canção pela segunda vez: tree, ghetto, salt, bitter, smell, fruit, sweet, black, blood, South, eyes, trees, rain, sun.

Antes de tocar a canção pela segunda vez, ocorre a leitura em coro da lista de palavras, seguida do esclarecimento sobre sua tradução. Em uma das turmas, o $3^{\circ} \mathrm{B}$, logo após a leitura das expressões, ocorre uma tentativa de relacionar as palavras articulando-as a uma narrativa antecipadora da letra da música da qual tais vocábulos foram extraídos, como se observa no trecho abaixo, de uma aluna:

\section{Trecho 5}

M: Tem uma morte aqui, mas não é uma morte qualquer. A gente tem doce... Tenho, o que é rain mesmo? Chuva, tenho sun que é sol, tenho as trees que são as árvores. O que essas coisas têm em comum?

D1: É porque quando matou, aí estava sol, aí choveu.

(TRANSCRIÇÃO DE TRECHO DE AULA) - $3^{\mathrm{a}}$ Etapa B (canção Strange Fruit)

Na sequência, os estudantes receberam a letra da canção, juntamente com instruções sobre a atividade de compreensão oral, isto é, preencher as lacunas com as palavras dadas. Como se verifica, boa parte da sequência de atividades se dedica ao desenvolvimento linguístico de compreensão auditiva, com o apoio de componentes narrativos, contextuais, melódicos e lexicais. Tal variedade de elementos assegurou a abrangência do trabalho pedagógico, proporcionando significativa proximidade do letramento social dos alunos, o que os motivou a buscarem, em seu repertório, ferramentas para a realização da atividade escolar.

Assim, cumpriu-se o objetivo, postulado no Caderno de orientações didáticas para EJA Língua Estrangeira - Inglês (SÃO PAULO, 2010), de conduzir os alunos à compreensão 
de língua como um fenômeno de múltiplas faces em operação, como as funções comunicativas, as estruturas gramaticais, o léxico, a construção de sentidos em um texto norteada pelo contexto.

Discutir o tema do racismo por ocasião de uma data comemorativa presente no cotidiano $^{8}$ pode ser também compreendido como uma medida pedagógica sensível ao letramento de mundo dos alunos, combinado ao conhecimento do contexto histórico e ao posicionamento crítico. Ou seja, questionar o conteúdo e as implicações do Dia da Consciência Negra, uma data que pode passar irrefletida para muitos, como ocorre com outros feriados, concretiza um fazer pedagógico respeitoso para com a cotidianidade, mas construtivo de criticidade, baseando-se em saberes mais sistematizados e menos ingênuos acerca do mundo, conforme defende Freire (1982). Vale ressaltar que o tema é caro entre os alunos de EJA, visto que a população negra apresenta, proporcionalmente, os índices mais altos de analfabetismo no Brasil ${ }^{9}$, se comparada à população de brancos. Reflexo dessa relevância se verifica no fato de, ao longo da aula, diversos alunos terem narrado situações de racismo. Ao mesmo tempo, percebe-se o alcance de outro objetivo educacional da língua estrangeira, conforme o Caderno de orientações didáticas para EJA Língua Estrangeira Inglês (SÃO PAULO, 2010), que é o de refletir a partir de outros loci sociais, uma vez que o exercício com a canção permitiu o reconhecimento de $\mathrm{si}^{10}$ e de outras posições sociais, se contemplados os alunos não negros e o convite à reflexão sobre fatos situados nos Estados Unidos do início do século XX, em vez da realidade imediata.

Além da vivência direta de situações em que o racismo é visível, entre os próprios estudantes ou seus familiares, amigos e conhecidos, a discussão sobre a incidência de racismo nos Estados Unidos, contexto da canção, é conduzida a partir de perguntas da professora Milena. Pensamos terem sido recursos de referência os artefatos da cultura midiática, tais como filmes, canções, notícias de jornal e de telejornal, dentre outros, corroborando Hall (1997), quando aponta para os discursos difundidos pela mundialização da mídia, e valorizando a ação pedagógica frente à sua importância como fonte de informação e formação (GIROUX; SIMON, 1989).

\footnotetext{
${ }^{8} \mathrm{O}$ feriado municipal do Dia da Consciência Negra, dia 20 de novembro.

${ }^{9}$ Conforme aponta, por exemplo, o documento de preparação para a mais recente CONFITEA, a VI Conferência Nacional de Educação de Adultos, com dados de 2006: 14\% entre a população negra e 6,5 \% entre a população branca, o que equivale a mais do que o dobro. Disponível em: http://portal.mec.gov.br/dmdocuments/confitea_docfinal.pdf Acesso em: 18 dez. 2017.

10 Com base em fotografias tiradas durante as aulas, notou-se uma média de 20 a $50 \%$ de estudantes negros nas turmas observadas.
} 
Passemos ao último trecho em análise, correspondente a uma atividade proposta $\mathrm{e}$ executada pela professora Vívian em que também se articularam os letramentos sociais aos letramentos escolares por meio da apreciação e prática de compreensão auditiva de uma canção. Frisamos que, durante o período de geração de dados, Vívian utilizou duas canções do repertório popular em língua inglesa, sendo uma delas "What a wonderful world" (1967), de Bob Thiele e George Weiss, popular pela interpretação do cantor e trompetista Louis Armstrong.

Para os fins deste artigo, abordaremos somente as atividades com a canção "What $a$ wonderful world", cuja proposta pode ser comparada à da professora Milena, discutida anteriormente, focalizando um tema que se desenvolvia em outras atividades pedagógicas. $\mathrm{O}$ tema, neste caso, foi "Saúde e corpo humano", desdobrado sob os aspectos de alimentação e de recursos naturais, como se observa no trecho de aula abaixo transcrito:

\section{Trecho 6 \\ V: Vamos dar uma olhadinha na letra, porque a letra vai falar sobre um assunto muito importante que a gente vem falando muito, de alimentação e de natureza. $\mathrm{O}$ que vocês estão vendo no fundo da imagem [referindo-se à reprodução da letra da música no material didático, contendo uma imagem do planeta Terra]? \\ B1: O planeta. \\ V: O planeta Terra. Então, nesta música, vocês vão ouvir sobre o planeta Terra. Nesta música, vocês vão ouvir sobre o tema gerador desse ano, as relações humanas. \\ (TRANSCRIÇÃO DE TRECHO DE AULA) - $3^{\mathrm{a}}$ Etapa D (canção What a wonderful world)}

De acordo com reportagem da rede $\mathrm{BBC}^{11}$, a canção "What a wonderful world", produzida em momento de intensa luta do Movimento dos Direitos Civis dos Negros, guarda uma mensagem política de apaziguamento entre negros e brancos, visto que, em 1968, ano de lançamento da canção, violentos protestos em torno da questão racial emergiram. $\mathrm{O}$ tom esperançoso e pacífico da canção, aliado à voz de um famoso cantor negro como Louis Armstrong, portanto, contrasta com as tensões daquele contexto. Apesar das motivações contextuais e políticas à canção, a professora Vívian contempla apenas a popular mensagem de otimismo.

$\mathrm{Na}$ atividade, Vívian traz à sala de aula um violão e refere-se à letra da música, reproduzida no livro didático e adaptada pela professora como um exercício de completar lacunas com palavras pré-selecionadas. Depois da justificativa, como notado no trecho acima, e com a observação da imagem apresentada no material, distribui aos alunos a atividade de completar lacunas e ensina a pronúncia de palavras, grupos de palavras e versos, pedindo para

\footnotetext{
${ }^{11}$ Disponível em: http://www.bbc.com/news/magazine-16118157 . Acesso em: 18 dez. 2017.
} 
que os alunos os repitam. Vívian discute o significado de alguns vocábulos e expressões mais longas, como vemos abaixo:

\section{Trecho 7}

V: I see, see é do verbo ver. Eu vejo. O que eu vejo? I see trees. O que será que são trees? Na natureza, algumas são bem grandonas, às vezes são bem pequenininhas. B1: Árvores.

V: As árvores, trees. E de que cor elas se vestem?

B2: Verde.

V: Green, verde. Olha que legal. Tem até o Greenpeace, que é uma entidade muito famosa, o Greenpeace. É a paz verde. Green, verde. Green é uma cor, um adjetivo. Uma qualidade, uma característica dessa árvore.

(TRANSCRIÇÃO DE TRECHO DE AULA) - $3^{\text {a }}$ Etapa D (canção What a wonderful world)

Após a discussão de cada estrofe, a professora retoma a tradução dos trechos para o português. Em seguida, toca a canção no violão e pede aos alunos que a acompanhem. Sem parar de tocar, a professora antecipa alguns trechos e aponta o verso (ou linha) em que a canção está, para ajudar a turma. Os alunos respondem e, em geral, cantam junto.

$\mathrm{Na}$ aula seguinte, os alunos foram levados ao laboratório de informática para assistirem na internet, pelo YouTube, a um vídeo da canção. Conforme esclarece Vívian na ocasião, o vídeo havia sido produzido por um internauta, e continha a letra da canção, acompanhada de imagens que se combinavam à compreensão de seu sentido. Segundo a professora, nesse dia, os alunos foram bem sucedidos ao cantar a música, superando algumas inquietudes notadas na primeira aula desta sequência. Embora não tocando em aspectos situacionais da canção, a atividade relacionou o tema estudado, isto é, a alimentação e a natureza. Com o texto da canção, os alunos tiveram a oportunidade de conhecer e reconhecer vocábulos e expressões em uso, abrangendo a oralidade, aspectos fonéticos e lexicais.

$\mathrm{Na}$ ausência de glossário no material didático, a professora Vívian esclareceu os sentidos da letra da canção dialogando e fazendo perguntas que acentuavam os letramentos sociais dos alunos. Em determinados momentos, Vívian optou por não traduzir, mas compartilhar exemplos e definições em língua portuguesa, o que auxiliou os alunos na construção de sentidos, partindo de compreensões e vivências próprias, isto é, o repertório metalinguístico adquirido não apenas na instituição escolar, mas, principalmente, fora dela.

Como já mencionado, a professora estimulou os alunos a acompanharem para cantar. Isso implicou um reposicionamento diante da tarefa, posto que alguns alunos expõem ser difícil cantar e aprender inglês, o que gerou uma breve discussão sobre as possibilidades na aprendizagem do idioma. Outros comentários seguem nesse sentido, mas chama a atenção o dizer de uma aluna, para quem não é possível aprender inglês na escola, somente "na 
convivência". Como se acentua em nossa discussão, este é um exemplo de comparação e confronto entre as percepções de letramentos escolares e os letramentos sociais. Reproduzimos, abaixo, o comentário da aluna:

\author{
Trecho 8 \\ B1: Desse jeito, a gente não aprende, não. A gente aprende com convivência, falando. \\ $\mathrm{V}$ : Também. Se aprende de várias formas. \\ B2: O que a gente aprende aqui, só aqui, a gente vai pra casa e aí, só semana que vem. \\ A gente esquece tudo. \\ V: Pode pegar na internet essa música. "What a wonderful world". \\ [vários alunos falam ao mesmo tempo] \\ B2: A maioria das pessoas não sabe nem português direito. \\ V: Será que o inglês não ajuda a falar melhor o português também? \\ [vários alunos falam ao mesmo tempo] \\ B3: Sempre tem música em Inglês na rádio.

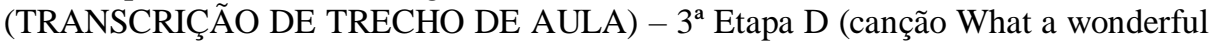 \\ world)
}

A aluna B1 caracteriza as práticas de aprendizagem via letramento escolar como restritas ao espaço e ao tempo da escola, e com pouca articulação às práticas cotidianas, por ocorrerem "uma vez por semana". A professora Vívian, em contrapartida, evoca uma prática de letramento social viabilizadora da aprendizagem escolar: ler a letra da canção em um website da internet. Junto à proposição de Vívian, ocorre a alegação de B3, ao lembrar à turma outra prática de letramento social: ouvir músicas em inglês nas estações de rádio, logo, sendo possível praticar o idioma em uma atividade cotidiana.

Esboçamos dois caminhos de reflexões neste ponto. No primeiro deles, corrobora-se a percepção de indissociabilidade entre o letramento social e o letramento escolar entre os estudantes. No segundo, busca-se articular os letramentos sociais e escolares em uma proposta educacional inovadora e condizente com as necessidades do aluno de EJA.

Conforme nosso primeiro caminho, B1 atribui ao letramento social a única possibilidade de usar o idioma, via aprendizagens informais por convivência com pessoas que usem inglês. Dentre as situações favorecedoras está a experiência de viver em um país de língua inglesa. Observamos, nisso, um efeito do mito do falante nativo (KUMARAVADIVELU, 2012; RAJAGOPALAN, 2003), legitimando apenas os conhecimentos e experiências de aprendizagem centralizados nos países de língua inglesa e, por consequência, marginalizando os eventos de aprendizagem e letramento ocorridos em diversas outras circunstâncias. Trilhando o mito do falante nativo ainda existe o apelo mercadológico em torno dos intercâmbios, como se sugere pela afirmação de que não há outras maneiras de se aprender uma língua estrangeira. 
Em um segundo caminho, por outro lado, a sugestão de B1 pode referir-se ao contato com outros usuários de inglês em situações de aprendizagem atreladas a um convívio social, o que se aproxima do que sugerem Kalantzis e Cope (2012) em sua proposta de comunidades de aprendizagem em que professores constroem ambientes sociais, articulando-se letramentos sociais e escolares, para que educandos possam aprender uns com os outros. Nessa dinâmica, os educandos se motivam porque a aprendizagem que os professores concebem engaja os aprendizes em experiências e identidades múltiplas, significativas no sentido de aplicações de vida em potencial (KALANTZIS; COPE, 2012).

Em nossa leitura, tais incômodos quanto à aprendizagem de inglês decorreram do desafio de abandonar a passividade ${ }^{12}$ frente à língua para adotar uma postura de ação, ou seja, de não apenas escutar a canção, mas de buscar cantá-la. A mudança de posicionamento envolve lidar com receios e preconceitos advindos do senso de incapacidade que se constrói nesses aprendizes em relações de poder que abrangem o domínio de línguas estrangeiras, o que também ocorre em relação a variedades prestigiadas da língua materna, legitimadas pela instituição escolar, corroborando o esclarecimento de Faria e Paula (2009). Conforme a fala da aluna B2: "A maioria das pessoas não sabe nem Português direito."

$\mathrm{Na}$ resistência em cantar e nas falas de B1 e B2 evidenciam-se relações de poder subjacentes ao ensino de língua estrangeira já apontadas por estudos pós-coloniais e pósestruturalistas, como a Linguística Aplicada Crítica de Rajagopalan (2003) e de Kumaravadivelu (2012), segundo os quais o ensino de inglês como língua estrangeira ao redor do mundo se sustentou sobre relações neolocoloniais hierarquizantes, centralizadas no mito do falante nativo e em seu aliado, o mito da competência do falante nativo, referindo-se aos falantes nascidos em países anglófonos. Esses falantes têm sido recorrentemente reverenciados como modelo de correção expressiva, gerando uma busca idealizada, por parte dos falantes não nativos, de aproximarem suas competências comunicativas às dos falantes não nativos. Consequentemente, são deslegitimados e desvalorizados a expressão e os conhecimentos dos falantes não nativos. Com isso, desenvolve-se uma dependência epistêmica entre professores e alunos de inglês como língua estrangeira, resultando na marginalização de falantes não-nativos e, consequentemente, acentuando relações neocoloniais (KUMARAVADIVELU, 2012, p. 5). Esse processo resulta na diminuição da

\footnotetext{
${ }^{12}$ Embora se entenda que a recepção de bens simbólicos não seja um ato estritamente passivo, pois demanda a interpretação desses signos, em si, uma ação inscrita em um contexto que é referido no ato mesmo de construir significados, conforme elucidação de Ricoeur (1972).
} 
autoestima de aprendizes, os quais acreditam que a língua estrangeira e sua respectiva cultura são superiores às suas próprias (RAJAGOPALAN, 2003, p. 68).

\section{Considerações finais}

Neste artigo, tratamos de evidenciar as relações entre letramento escolar, isto é, as práticas de aprendizagem sistematizada próprias da instituição escolar, e letramento social, ou as aprendizagens advindas das vivências sociais dos aprendizes, conforme geração de dados ocorrida em aulas de língua inglesa em pesquisa de cunho etnográfico em duas comunidades escolares compostas por duas professoras e suas turmas de EJA na cidade de São Paulo em 2012. Selecionamos dois exemplos de sequências didáticas observadas em cada comunidade escolar, a fim de discutir momentos em que houve distanciamento ou aproximação entre os dois tipos de letramento.

Em ambas as comunidades escolares, mesmo em projetos norteados por eixos temáticos transversais e interdisciplinares, como a abordagem da geração e uso de energia empreendida pela professora Milena e a proposta de confecção e discussão sobre brinquedos de criança, da professora Vívian, conforme indicam as Orientações Didáticas para o Ensino de Língua Estrangeira na EJA (SÃO PAULO, 2010), a articulação entre os saberes sociais e a língua inglesa ocorreu via léxico, limitando as possibilidades de conhecimentos de contexto e aspectos mais variados da diversidade linguística.

Em uma articulação mais frutífera, foi observada a valorização dos conhecimentos de mundo a partir do uso de canções articuladas a temas, tais como "Strange Fruit", para discutir o Dia da Consciência Negra, nas aulas da professora Milena, e "What a wonderful world", para sensibilizar sobre a natureza e a alimentação, nas aulas da professora Vívian. Ainda assim, observou-se que, em alguns momentos, os letramentos sociais e os escolares podem estar em confrontação, e não em complementação, evidenciando concepções problemáticas sobre língua e aprendizagem pertinentes ao ensino de língua estrangeira em contexto de relações de poder, tais como o mito do falante nativo (KUMARAVADIVELU, 2012; RAJAGOPALAN, 2003) como forma de hierarquização epistêmica e marginalização de aprendizes não nativos.

Defende-se, portanto, que o ensino de língua inglesa, seguindo os pressupostos dos estudos de letramentos presentes nas orientações didáticas para a educação básica (BRASIL, 2006; 2013) e na EJA em específico (SÃO PAULO, 2010), seja sensível aos conhecimentos 
de mundo e de contexto dos alunos, de modo a torná-los cientes de sua posição no mundo e oportunizando-se transformações sociais a partir de tais conhecimentos.

Aponta-se a necessidade de continuidade de pesquisas que envolvam o uso de mídias e tecnologias digitais, uma vez que elas se transformam constantemente e avançam sobre a cotidianidade de uma parcela cada vez maior de pessoas, impactando tanto os letramentos sociais quanto os letramentos escolares, o que demanda teorização de práticas que possam articulá-los.

\section{Referências bibliográficas}

BARTON, David. Literacy: An Introduction to the Ecology of Written Language. Oxford: Blackwell Publishing, 1994.

BOURDIEU, Pierre. A economia das trocas simbólicas. São Paulo: Perspectiva: 2011.

BRASIL. Ministério da Educação (MEC), Secretaria de Educação Básica. Orientações Curriculares para o Ensino Médio - Língua Estrangeira, 2006. p.83-124

BRASIL, Ministério da Educação. Diretrizes Curriculares Nacionais Gerais da Educação Básica. Brasília: MEC, SEB, DICEI, 2013.

CERVETTI, Gina; PARDALES, Michael J.; DAMICO, James S. A tale of differences: comparing the traditions, perspectives, and educational goals of critical Reading and critical literacy. Reading online, 9. 2001. Em: http://www.readingonline.org/articles/cervetti/. Acesso em: 07 dezembro 2012.

COPE, Bill; KALANTZIS, Mary. (eds.). Multiliteracies: literacy learning and the design of social futures. London: Routledge, 2003.

DUBOC, Ana Paula Martinez. A questão da avaliação da aprendizagem de Língua Inglesa segundo as teorias de letramentos. Dissertação (Mestrado em Estudos Linguísticos e Literários em Inglês). Faculdade de Filosofia, Letras e Ciências Humanas, Universidade de São Paulo, São Paulo, 2007.

FARIA, Núbia R.B.; PAULA, Aldir S. Refletindo sobre falar e escrever em EJA. Campinas: Ministério da Educação, Cefiel/IEL/Unicamp, 2009.

FÁVERO, Osmar. Lições da história: os avanços de 60 anos e a relação com as políticas de negação de direitos que alimentam as condições do analfabetismo no Brasil. In: PAIVA, Jane; OLIVEIRA, Inês. B. (orgs.). Educação de Jovens e Adultos. Petrópolis, RJ: DP et Alii, 2009. p. 9-21.

FERNANDES, Jaci C. A música desatando os nós no ensino de línguas. In: Congresso Internacional Da Associação Brasileira de Literatura Comparada, 11, 2008, São Paulo. 
Anais... São Paulo, SP - Tessituras, Interações, Convergências /Sandra Nitrini... et al. - São Paulo: ABRALIC, 2008.

FERRAZ, Daniel M. Letramento Visual: A leitura de imagens das aulas de inglês. Jundiaí: Paco Editorial, 2012.

FREIRE, Paulo. Pedagogia do Oprimido. $3^{\text {a }}$ ed. Rio de Janeiro: Paz e Terra, 1982.

GEE, James Paul. Situated language and learning: A critique of traditional schooling. New York, London: Routledge, 2004.

GHIRALDELLI JR., Paulo. Filosofia e história da educação brasileira. Barueri: Manole, 2003.

GIROUX, Henry; SIMON, Roger. (orgs.). Popular culture, schooling and everyday life. New York: Bergin \& Garvey, 1989.

HADDAD, Sérgio; DI PIERRO, Maria C. Escolarização de jovens e adultos. Revista Brasileira de Educação, n. 14, Mai/Jun/Jul/Ago, 2000.

HALL, Stuart. The centrality of culture: notes on the cultural revolutions of our time. In: THOMPSON, Kenneth (ed.). Media and cultural regulation. London, Thousand Oaks, New Delhi: The Open University; SAGE Publications, 1997. Publicado em Revista Educação \& Realidade, Trad. Ricardo Uebel, Maria Isabel Bujes e Marisa Vorraber Costa.

JANKS, Hillary et al. Doing critical literacy: texts and activities for students and teachers. New York, London: Routledge, 2014.

JORDÃO, Clarissa M.. Abordagem comunicativa, pedagogia crítica e letramento crítico farinhas do mesmo saco? In: ROCHA, Cláudia H.; MACIEL, Ruberval F. (orgs.). Língua Estrangeira e Formação Cidadã: por entre discursos e práticas. Campinas-SP: Pontes Editores, 2013. p. 69-90.

KALANTZIS, Mary; COPE, Bill (orgs.). Learning by Design. University Press: Melbourne, 2005.

KALANTZIS, Mary; COPE, Bill. Ubiquitous Learning: An Agenda for Educational Transformation. In: (orgs.) Ubiquitous learning. Urbana and Chicago: University of Illinois Press, 2010.

KALANTZIS, Mary; COPE, Bill. Literacies. New York: Cambridge University Press, 2012a.

KALANTZIS, Mary; COPE, Bill. Learning communities at work. In: New Learning: Elements of a science of education. Melbourne: Cambridge University Press, 2012b. p. 210-227. 
KUMARAVADIVELU, B. Individual identity, cultural globalization, and teaching English as an international language; The case for an epistemic break. In: ALSAGOFF, Lubna; MCKAY, Sandra L.; HU, Guang; RENANDYA, Willy. A (eds.). Principles and practices for teaching English as an international language. New York: Routledge, 2012. p. 9-27.

LANDIM, Denise Silva Paes. O inglês da EJA para a vida: letramentos sociais e escolares refletidos. Dissertação (Mestrado em Estudos Linguísticos e Literários) - 239 páginas. Faculdade de Filosofia, Letras e Ciências Humanas, Universidade de São Paulo, São Paulo, 2015.

LANKSHEAR, Colin; KNOBEL, Michelle. New Literacies: Everyday Practices and Social Learning. Berkshire, England: Open University Press Mc Graw-Hill Education, 2011.

LUKE, Allan; FREEBODY, Peter. Shaping the social practices of Reading. In: MUSPRATT, Sandy; LUKE, Allan.; FREEBODY, Peter. Constructing critical literacies: teaching and learning textual practice. Cresskill: Hampton Press, 1997. p. 185-225.

MENEZES DE SOUZA, Lynn Mario T. Para uma redefinição de Letramento Crítico: conflito e produção de significação. In: MACIEL, Ruberval F. \& ARAÚJO, Vanessa A. (orgs).

Formação de Professores de Línguas: ampliando perspectivas. São Paulo: Paco Editorial, 2011. p.128-140.

MONTE MÓR, Walkyria. The development of agency in a new literacies proposal for teacher education in Brazil. In: JUNQUEIRA, Eduardo S.; BUZATO, Marcelo. (eds.) New literacies, new agencies? A Brazilian perspective on mindsets, digital practices and tools for social action in and out of school. New York: Peter Lang, 2013. pp.126-146.

MOITA LOPES, Luiz Paulo da (org.) Por uma linguística aplicada INdisciplinar. São Paulo: Parábola Editorial, 2006.

MOURA, Tania M. M. Alfabetização e Letramento na formação de alfabetizadores de jovens e adultos. In: (org.). A formação de professores para EJA: dilemas atuais. Belo Horizonte: Autêntica, 2007. p. 11-38.

PENNYCOOK, Alastair. Critical and alternative directions in applied linguistics. Australian Review of Applied Linguistics 33 (2), 16.1-16.16. DOI: 10.2104/aral1016. University Press, 2010a.

RAJAGOPALAN, Kanavillil. Por uma linguística crítica: linguagem, identidade e a questão ética. São Paulo: Parábola Editorial, 2003.

REAGAN, Timothy. Objectification, positivism and language studies: A reconsideration. Critical Inquiry in Language Studies, v. 1, n. 1, p. 41-60, 2009.

RICOEUR, Paul. O conflito das interpretações: ensaios de hermenêutica. Rés Editora, 1972. 
ROCHA, Cláudia H.; MACIEL, Ruberval F. Língua Estrangeira, Formação Cidadã e Tecnologia: ensino e pesquisa como participação democrática. In: (orgs.) Língua Estrangeira e Formação Cidadã: Por entre Discursos e Práticas. Campinas, SP: Pontes Editores, 2013. p. 13-29.

SÃO PAULO (SP). Secretaria Municipal de Educação. Diretoria de Orientação Técnica. Caderno de Orientações didáticas para EJA Língua Estrangeira - Inglês: etapas complementar e final - São Paulo: SME / DOT, 2010.

SÃO PAULO (SP). Secretaria Municipal de Educação. Diretoria de Orientação Técnica. Orientações Didáticas: Alfabetização e Letramento - EJA e MOVA. São Paulo: SME / DOT, 2007.

SARTORI, Anderson. Legislação, políticas públicas e concepções de Educação de Jovens e Adultos. In: LAFFIN, Maria Hermínia L.F. (org.) Educação de Jovens e Adultos e Educação na Diversidade. Florianópolis. UFSC. 2011. p. 14-125.

SOARES, Magda. Letramento e Escolarização. In: RIBEIRO, Vera M. Letramento no Brasil. São Paulo: Global, 2003, p. 89-113.

STREET, Brian V. Letramentos sociais: abordagens do letramento no desenvolvimento, na etnografia e na educação. São Paulo: Parábola, 2014.

Recebido em 29 de dezembro de 2017. Aceito em 16 de outubro de 2018. 